\title{
CDNA Microarray Analysis
}

National Cancer Institute

\section{Source}

National Cancer Institute. cDNA Microarray Analysis. NCI Thesaurus. Code C25866.

Complementary DNA (CDNA) clone inserts robotically printed onto a glass slide and subsequently hybridized to two differentially fluorescently labeled probes. The probes are pools of cDNAs, which are generated after isolating mRNA from cells or tissues in two states that one wishes to compare. 